\title{
Paul-Ludwig Weinacht
}

\section{Eroberungskrieg und Propaganda der Verteidigung Recht - Diskreditierung - Verbot}

"Unter politischer Gemeinschaft wollen wir eine solche verstehen, deren Gemeinschaftshandeln dabin verläuft: sein Gebiet....und das Handeln der darauf... befindlichen Menschen durch Bereitschaft zu physischer Gewalt, und zwar normalerweise auch Waffengewalt, der geordneten Beherrschung durch die Beteiligten vorzubehalten (und eventuell weitere Gebiete für diese zu erwerben). "1

Der kriegerische Angriff und die mit ihm verbundenen Eroberungen sind ein klassischer Ausdruck des ius belli. Souveräne Staaten haben danach das Recht, ihre Händel als gleichberechtigte Kriegspartner untereinander auszutragen, und zwar unabhängig von der Unterscheidung nach Angriff und Verteidigung. ${ }^{2}$ Die Unterscheidung von erlaubter Verteidigung und unerlaubtem Angriff, im 19. Jahrhundert angesichts der napoleonischen Kriegszüge hervorgebracht, wurde im 20. Jahrhundert ins Völkerrecht überführt. ${ }^{3}$ Und doch scheint das Völkerrecht seit dem 11. September 2001 ins Rutschen geraten zu sein: Eine außenpolitische Schule in den USA hält dafür, dass anticipatory military activities, sprich »militärischer Angriff «, unter der Bezeichnung von preemption eine Art von erlaubtem Verteidigungskrieg sei. ${ }^{4}$

Moraltheologen waren seit dem Mittelalter bemüht gewesen, plausible Kriterien für ein bellum iustum (Thomas v. Aquin) zu finden. Sie wollten verhindern, dass aus kleinen Anlässen und in beliebiger Absicht militärische Interventionen vom Zaun gebrochen werden. Mit der katholischen Conquista verdichteten spanische Theologen ihre theologisch-ethischen zu juristischen Argumenten. Dem Anspruch der Staaten auf ein Recht zum Krieg in der Absicht, »eventuell weitere Gebiete...zu erwerben« (M. Weber), wurde von einer frühliberalen bürgerlichen Öffentlichkeit die Rechtfertigung bestritten. Benjamin Constant sprach weithin vernehmbar ein moralisches Verdikt über den Kriegsherrn der Epoche. Anlaß war ihm der Aufbruch der Grande Armée zur Unterwerfung und Eroberung Rußlands. In seinem in Mon-

1 Max Weber, Wirtschaft und Gesellschaft, Kapitel VIII (Politische Gemeinschaften), Tübingen 1976, S. 514.

2 Carl Schmitt, Der Nomos der Erde, Berlin 1950, S. 114 f.. Zum Zusammenhang von ius belli und iustus hostis vgl. ders., Der Begriff des Politischen, Text v. 1932 mit einem Vorwort und drei Corollarien, Berlin 1963, S. 46.

3 Gewöhnlich wird der Brand-Kellogg Pakt von 1928 als erstes völkerrechtlich verbindliches Dokument des Verbots des Angriffskriegs genannt.

4 Rachel Bzostek, Why not Preempt? Security, Law, Norms and Anticipatory Military Activities, California State University 2008. 
tesquieus Geist ${ }^{5}$ verfaßten Traktat De l'esprit de conquête et de l'usurpation, dans leurs rapports avec la civilisation européenne dekretierte er, dass Krieg in keiner Form erlaubt sei und Waffen nur gegen Angreifer geführt werden dürften. Im letzteren Fall gehe es »nicht um Krieg im eigentlichen Sinne«, sondern »um gerechte Verteidigung, d. h. um Vaterlandsliebe, um Liebe zur Gerechtigkeit, um alle edlen und geheiligten Gefühle«. ${ }^{6}$ Sein Traktat weist damit über die unmittelbare Veranlassung des Herbstes 1813 hinaus. Noch in der Mitte des vergangenen Jahrhunderts galt Constant, der Repräsentant der liberalen europäischen Zivilisation ${ }^{7}$, als geistiger Zertrümmerer des Eroberungskriegs. ${ }^{8}$

Eroberungskriege konnten schon im 17. und 18. Jahrhundert als ungerecht gelten. Was Constant dem Argument fehlender Rechtfertigung hinzufügt, ist das zivilisatorische Argument: Eroberungskriege seien anachronistisch geworden, weil sie eine überholte Form des Eigentumswechsels darstellten. Moderne Völker bevorzugten aus guten Gründen den Handel: »Krieg und friedlicher Austausch sind nichts als zwei verschiedene Mittel zum gleichen Ziel, nämlich zum Besitz dessen, was man begehrt...Die Erfahrung, dass der Krieg, also die Anwendung eigener Gewalt gegen die Gewalt eines anderen, ihn vielfachem Widerstand und Misserfolg aussetzt, lässt ihn zum friedlichen Austausch als dem sanfteren und sichereren Mittel greifen, durch welches er das fremde mit dem eigenen Interesse versöhnt. « Große Eroberer, die vormals Ansehen und Verehrung genossen, stünden heute moralisch auf verlorenem Posten: »Wenn die Menschen, die das Schicksal der Welt in Händen halten...gegen die Interessen, gegen den ganzen sittlichen Daseinsgrund ihrer Zeitgenossen kämpfen, wenden sich diese Kräfte des Widerstands gegen sie; und nach einiger Zeit, lang genug für die Opfer, kurz für das Maß der Geschichte, bleiben von ihren Unternehmungen nur die Verbrechen, die sie begingen, und die Leiden, die sie verursacht. «10

Constant endet seine Philippika gegen das napoleonische Eroberungssystem damit, dass er den Eroberer aus der zivilisierten Menschheit ausschließt (»Mensch einer anderen Welt «) und die von ihm betriebene Politik aus aller moralischen Zeitgenossenschaft verbannt: »Das System der Eroberung, dieses Überbleibsel eines

5 Schon der Titel des Traktats von Constant wirkt wie eine Ergänzung des Esprit des lois. Im 12. Kapitel des Traktats (»Wirkung dieser Erfolge auf die unterworfenen Völker«) wird ausführlich aus Esprit des lois, Buch X, Kapitel 3 zitiert. In Kapitel 13 des Traktats wird Montesquieu als Autorität beschworen.

6 Benjamin Constant, Über die Gewalt.Vom Geiste der Eroberung und der Anmaßung der Macht, aus dem Französischen von H. Zbinden, (= Reclam Nr.7618-20), Stuttgart 1948, S.11.

7 Carl Schmitt nennt Benjamin Constant den »Inaugurator der gesamten liberalen Geistigkeit des 19. Jahrhunderts", vgl. Carl Schmitt, Der Begriff des Politischen, 6. Aufl., Berlin 1996, S.73.

8 Im Jahr 1942 wurde der Text ins Deutsche übersetzt, 1947 erschien eine Neuausgabe, 1948 im Stuttgarter Reclam-Verlag die deutsche Übersetzung.

9 Constant, Über die Gewalt, Stuttgart 1948, S.13 f.

10 Constant, ebd. S.7 f. 
verschwundenen Zustandes, dieser Zersetzer alles Bestehenden, wäre erneut von der Erde verbannt, und durch diese letzte Erfahrung verdammt zu ewiger Schmach. «11 Solche Sätze könnten eine ältere von einer jüngeren Epoche der Menschheitszivilisation trennen. Wie sich unsere Zeitgenossen dazu verhalten, die im Zeitalter der Ideologien, Krieg geführt haben und noch führen, steht auf einem anderen Blatt. ${ }^{12}$ Dass auf Annexion ausgehende Kriege, bei denen Massen beteiligt sind und das internationale System kriegsführende und neutrale Staaten kennt, auf vorbereitende Diplomatie und begleitende Propaganda angewiesen sind, wissen wir nicht erst seit den europäischen Kriegen des 19. Jahrhunderts. Und doch hat sich im 20. Jahrhundert jene neue mediale Begleitpraxis zum Krieg gebildet, deren Ziel es ist, die eigene Sache der moralischen Verurteilung zu entziehen, die des Feindes aber desto schwärzer hineinzutauchen.

Im Folgenden diskutieren wir den Krieg anhand von Texten, die in einer Zeit entstanden, als Kriege auszulösen und zu führen zum Recht souveräner Staaten gehörte. Es entsprach der Situation, dass Gebietsstreit, wo nicht durch Vereinbarung, nurmehr durch Rekurs auf Deus index, also im Glück der Waffen, entschieden werden konnte. ${ }^{13}$ Argumente klassischer Autoren werden vorgeführt anhand von Texten des Politikers Machiavelli (1469-1527), des Theologen Vitoria (um 1483 - 1546), des Juristen Montesquieu (1689 - 1755) und des Philosophen Kant (1724 - 1804). Der Zusammenhang von Eroberung und Krieg tritt dabei je anders in Erscheinung, und das nicht nur, weil je andere Überzeugungen vorherrschen, sondern weil verschiedener Zeiten und Länder unterschiedliche Probleme stellen: je andere im Italien der Medici, im Spanien Karls V., in Frankreich im Bann des Sonnenkönigs, in Preußen angesichts der Französischen Revolution. Zuletzt nehmen wir uns ein Beispiel amtlicher Kriegspropaganda vor, das geeignet ist zu zeigen, wie Staaten Krieg nicht nur führen, sondern auch seinen Verlauf interpretieren müssen. Unsere Quelle sind Erinnerungen des ersten amtlichen Propagandabeauftragten während des Ersten Weltkrieges, des Reichstagsabgeordneten Mathias Erzberger (1875 - 1921).

\section{Machiavelli}

In den wenig gefestigten italienischen Fürstentümern und Städten der Renaissance gehörten Herrschaftswechsel, wechselnde Bündnisse, Eroberung und Rückeroberung von Territorien zum normalen Gang der Politik. Geschäftserfahrene Di-

11 Constant, ebd. S. 52 f.

12 Carl Schmitt, Das international-rechtliche Verbrechen des Angriffskrieges und der Grundsatz "Nullum crimen, nulla poena sine lege", hg. und mit Anmerkungen versehen v. Helmut Quaritsch, Berlin1994.

13 Ein früher Text dazu wird zitiert nach Raphaelis Fulgosii, Super prima digesti veteris parte. Ex hoc iure, ed. Luguni DXLIIII, S. 205, vgl. P. Haggenmacher, Grotius et la doctrine de la guerre juste, Paris 1983. 
plomaten (»statisti«), wie Machiavelli einer war, prüften die Interessen und die Hilfsmittel. Sie wussten zu sagen, ob ein Fürst oder eine Bürgerschaft das Zeug zum Kampf habe (virtú), ob eine Entscheidung für einen Eroberungskrieg oder einen Waffenstillstand unvermeidlich seien (necessità), ob sich irgendeine günstige Gelegenheit zu einem Angriff oder einem Bündniswechsel ergäbe (fortuna). Machiavelli hat seine politisch-historischen Analysen im Principe nach den angedeuteten Gesichtspunkten angelegt und dabei, wie der Wechsel des Buchtitels wohl zeigt, unter der Hand weniger den Formen der Herrschaft (»De principatibus«) Aufmerksamkeit geschenkt als den politischen Akteuren (Il Principe, 1513).

Machiavellis Verständnis des Krieges beruht auf seiner Bewunderung für den militärischen Charakter (virtú) der Römer und ist eine Frucht seiner kritischen Beobachtung des zeitgenössischen Kriegswesens und seiner Folgen für die Staaten. Wer Eroberungen macht, muss mit Revanche rechnen und braucht dafür kalte Entschlossenheit. Die Römer besaßen davon genug und hätten daher nicht, wie seine italienischen Zeitgenossen, die Ausrede benutzt »kommt Zeit, kommt Rat «: »denn sie [die Römer] wußten, daß der Krieg nicht aufgehoben, sondern immer nur aufgeschoben wird - zum Vorteil der Gegner « (Principe, 3. Kapitel). Das Führen eines Kriegs war für ihn keine Frage von Moral und Recht, sondern von Planung, Geschicklichkeit und Tapferkeit, also eine quaestio facti. Der genialische Papstsohn Cesare Borgia vermochte die Fundamente, »die andere legen, ehe sie Fürst«, in der Romagna nachträglich zu errichten: durch geliehene Waffen, Unbedenklichkeit, militärische Führungskraft, Glück (Principe, Kapitel 7). Freilich verlor er alles wieder, als sein Vater nicht mehr lebte, weil er die nachfolgende Personalentscheidung unüberlegt traf (Papst Julius) und weil er in einem kritischen Zeitpunkt wegen Krankheit nicht präsent sein konnte. Alles dies Tatsachen-, keine Moral- oder Rechtsfragen.

Im Dienst der Republik machte sich Machiavelli 1506 das Kriegshandwerk zur Aufgabe ${ }^{14}$, wobei er zwei Reformziele verfolgte: Die Infanterie sollte der Kern der Streitkäfte werden und diese selbst sollten nicht länger aus Söldnern, sondern aus Bürgern bestehen. Auf die Weise wollte er den Krieg abkürzen und die Entscheidungsschlacht suchen, die von den Söldnern und ihren Führern (Condottiere) bekanntlich eher gemieden wurde. Unter wiederholtem Verweis auf eine Lage, die andere Lösungen nicht erlaube (necessità), empfahl er dem Großen Rat seiner Vaterstadt ein Gesetz zur Aufstellung einer Bürgermiliz aus Infanteristen, die, wo

14 Während Villari im Blick auf Machiavells Miliz-Konzept im Licht der Ereignisse von 1512 von »Illusionen « spricht, bewundert Giuseppe Bonghi seinen großen Landsmann im Licht seiner Kriegskunst-Schrift von 1521 als Vorläufer Clausewitz'. Vgl. zu Bonghi: Introduzione a Dell'arte della guerra di Machiavelli, edizione telematica et revisione, Iuglio 1997. Dass Milizen eine »Niederwerfungsstrategie« nach außen möglich machten und nach Innen den bürgerschaftlichen Geist (virtì) gesunden ließen, betont nachdrücklich Herfried Münkler, Machiavelli. Die Begründung des politischen Denkens der Neuzeit aus der Krise der Republik Florenz, Frankfurt/M. 1982, S. 381-394. 
nicht gleich aus der Stadtbürgerschaft, so wenigstens aus dem Landvolk im Umland (Contado) ausgehoben werden sollten. ${ }^{15}$

Dass Machiavellis Erwartung an die Überlegenheit von Bürgermilizen und ihre wohltätige Wirkung auf den politischen Charakter der Bürgerschaft übertrieben waren, zeigte sich zwar noch nicht beim ersten Einsatz der Bürgerstreitmacht 1509, der es durch Aushungerung der Einwohner von Pisa gelang, diese von Florenz abgefallene Stadt zurückzugewinnen, wohl aber beim zweiten Einsatz drei Jahre später, als professionell ausgebildete und geführte Soldaten im Sold der spanischen Krone den florentinischen Vorort Prato einnahmen und völlig zerstörten. Damals liefen die Milizionäre aus dem Umland (Contado) von Florenz demoralisiert davon. Die Niederlage bedeutete das Ende der Soderini-Republik, in der Machiavelli seinen politischen Einfluß besaß und die Rückkehr der Medici an die Macht in Florenz.

Obwohl es ihm vor allem um die Sicherung der republikanischen Freiheit seiner Vaterstadt gegangen war ${ }^{16}$, hat er auch die politischen Probleme einer Fürstenherrschaft analysiert: der ererbten und der neuen. Eroberungen, die ein Erbfürst machen kann, behandelt er als »zusammengesetzte Fürstentümer « (Principe, Kapitel 3); sie $\mathrm{zu}$ errichten verlange nicht viel mehr als dies: alte Gewohnheiten der neu gewonnenen Untertanen zu respektieren. Ganz andere Schwierigkeiten türmen sich auf, wenn einer eine Herrschaft ganz neu begründen, d. h. einen stato erobern will, und wenn ihm dann auch noch die notwendigen Mittel abgehen (Principe, Kapitel 2). ${ }^{17}$

Das Erobern selbst, auf das Fürsten wie Privatleute aus sind, ist ihm etwas Natürliches. Es ist ihm so selbstverständlich wie den älteren Sozialphilosophen der Drang des einzelnen im Naturzustand, sich anderen anzuschließen und in Gesellschaft zu leben (ens sociale). Allerdings verabsolutiert er den Menschen nicht als ein ens expugnans, sondern stellt die Aktualisierung des natürlichen Eroberungsdrangs unter den Vorbehalt der Lage: »Die Eroberungslust ist etwas sehr Natürliches und Verbreitetes, und so oft Fürsten auf Eroberungen ausgehen, die die Macht dazu haben, werden sie gepriesen oder wenigstens nicht getadelt. Wenn ihnen aber die Kräfte zu Eroberungen fehlen und sie doch um jeden Preis solche machen wollen, so ist das verkehrt und verdient Tadel «(Principe, Kap. 3).

Wenn Republiken, Fürsten und Privatleute um Machtgewinn und Machterhaltung kämpfen, sind sie insofern nicht voneinander verschieden. Allenfalls unter-

15 "Questo ordine bene ordinato nel contado, de necessità conviene che entri ad poco ad poco nella città, et sarà facilissima cosa ad introdurlo. Et vi advedrete anchora a'vostri dì, che differentia è havere de'vostri cittadini soldati per electione et non per corruptione, come havete al presente... ", in: »Relazione del Machiavelli sulla istituzione della nuova Milizia", in: Pasquale Villari, Niccolò Machivelli e $i$ suoi Tempi illustrate con nuovi documenti, Bd. I, Florenz 1877, Doc. XXXVII, S. 641.

16 "potere preservare la vostra libertà" (Relazione [1877], S. 637).

17 Robert Shackleton meinte im Blick auf Machiavelli als Vorbild Montesquieus: »Machiavelli had written of republic and monarchy as good States and contrasted them with tyranny which was bad." Ders., Montesquieu. A Critical Biography, Oxford 1961, S. 267. 
scheiden sie sich darin, ob sie den Gewinn, den sie sich geholt haben, dauerhaft behalten oder rasch wieder einbüßen. Das politische Problem der Eroberung beginnt also mit dem militärischen Sieg und es ist völlig unabhängig von der Frage, ob der Sieger als Usurpator angesehen wird. Er vermeidet daher den Begriff. Denn worum es geht, ist, Konkurrenten und Unterworfenen die Aussicht auf Änderung der Verhältnisse zu nehmen bzw. sie hoffen zu lassen, dass die neue Herrschaft ihnen oder dem Vaterland gut bekommen könnte. Machiavelli hat in diesem Zusammenhang auch Privatleute als Staatsgründer behandeln können. Diese »wertfreie« Behandlung wurde von Jesuiten und Lutheranern scharf getadelt und noch Liberale des 20. Jahrhunderts wandten sich davon ab, als sie Bezüge zu jenem österreichischen Privatmann entdeckten, der vom Postkartenmaler zum Reichskanzler und militärischen Oberbefehlshaber aufstieg. ${ }^{18}$

Blutige militärische Eroberung verhindert die Gunst der Einwohner, auf die ein Eroberer angewiesen ist, um seinen Gewinn dauerhaft zu bewahren. Aus diesem Widerspruch entfalten sich die politischen Folgeprobleme nach dem Sieg. So heißt der erste politische Ratschlag: Das Loyalitätsband zur angestammten Dynastie müsse zerschnitten werden. Wenn die Untergebenen an Freiheit nicht gewohnt waren, müsse die Dynastie sogar ausgerottet werden. Der Eroberer solle nur die gewohnten »Gesetze und Abgaben« im Auge behalten. Wenn Sprache, Sitte und Verfassung fremd sind, empfiehlt Machiavelli dem Eroberer, den Wohnsitz im neuen Land aufzuschlagen, wie die Türken es in Griechenland getan hätten, oder Militärkolonien anzulegen. Das dafür erforderliche Gelände lasse sich durch die Vertreibung der Vorbesitzer gewinnen. Um handlungsfähig zu werden, möge er sich mit den Schwachen verbünden, ohne sie zu stark werden zu lassen, den alten Eliten aber das Wasser abgraben. Eine Nachbarmacht dürfe sich nicht als Retter aufspielen können (das war die klassische Strategie Athens, von der Thukydides berichtet). Schwierig sei es mit eroberten Republiken, die man eher »mit Hilfe ihrer eignen Bürger... behaupten als auf irgendeine andre Weise, wenn man sie nicht zerstören will.« Gelänge dies nicht, müsse man die Bürger austreiben, da Republikaner »ihre Freiheit und Verfassung nie" vergessen (Principe, Kapitel 5).

Im berühmten 26. und letzten Kapitel des Principe gibt Machiavelli den Blick auf die Eroberung der der nationalen Einigung im Weg stehenden Gebiete frei. Er zeichnet hier aber nicht das Bild kumulierter Annexionen als vielmehr einer fortschreitenden Desannexion ${ }^{19}$ : Worte können nicht sagen, mit welcher Liebe ihn all die Gebiete aufnehmen würden, die unter dem Einbruch der Fremden gelitten ha-

18 Für die jüngere Literatur dazu vgl. Gerhard Ritter, Die Dämonie der Macht, München 6 Aufl. 1948, Leo Strauss, Thoughts on Machiavelli, Glencoe 1958, Dolf Sternberger, Drei Wurzeln der Politik, Frankfurt/Main 1978 (bei Sternberger wird Machiavelli unter dem Rubrum »Dämonologik « und mit ausdrücklichem Verweis auf Hitler interpretiert: u. a. Röhmputsch als Sinigalia).

19 Der Begriff spielt in der Zeit zwischen dem Berliner Kongress und dem Ersten Weltkrieg auf dem Balkan eine überragende Rolle, vgl. z. B. D. Rizoff, Vorwort zu Die Bulgaren in ibren historischen, ethnographischen und politischen Grenzen, Berlin 1917, S. XII u.ö. 
ben, mit welchem Rachedurst, welcher unerschütterlichen Treue, welcher Ehrfurcht, welchen Tränen! Wie könnte sich ihm ein Tor verschließen, ein Volk den Gehorsam versagen, wie könnte gegen ihn Neid sich regen, wie ein Italiener ihm nicht huldigen: einen jeden ekelt die Herrschaft der Barbaren.« Machiavelli beschreibt hier den »Volksfürsten «, der in den eroberten Gebieten wie der Fisch im Wasser operiert und im Verhältnis zu den Landfremden alle Register der politischen und Kriegskunst zu ziehen vermag - ein neuer Borgia.

Die Einigung Italiens wäre die Voraussetzung dafür, dass nicht länger Privatleute ihren Eroberungsgelüsten nachgehen können, weil Krieg dann zur Angelegenheit von Völkerrechtssubjekten und mithin zu einer quaestio juris werden könnte.

\section{Francesco de Vitoria}

Der Dominikaner Vitoria kennt die Lehre des Aquinaten vom begrenzt gerechtfertigten Krieg (bellum iustum). Den von Machiavelli mehr geahnten als verbindlich wahrgenommenen Zustand des Krieges zwischen Staaten nimmt er in seinen relectiones (De Indis recenter inventis, 1539) auf und stellt ihn in dem aktuellen Fall der Eroberung »Indiens « durch die spanische Krone zur Diskussion. Anders als bei Machiavelli bleibt er nicht bei den Tatsachen stehen, sondern diskutiert das ihnen zugeordnete Recht. Die Diskussion pro und contra eruiert die inneren Schwächen und Stärken rechtfertigender Argumente.

Vitoria hat es darauf abgesehen, die bis dahin am Hofe Karls V. und Philipps II. gängigen Lehren eines Joan Gines Sepúlveda zu widerlegen, die darauf zielten, Indianer-»Land zum Objekt einer freien Landnahme ${ }^{20}$ zum machen, weil seine Besitzer Götzenanbeter und »Sklaven von Natur « (Aristoteles ${ }^{21}$ ) seien. Dagegen trägt Vitoria vor, Indianer besäßen die gleichen natürlichen Rechte und Institutionen wie Europäer, denn sie hätten Anteil an der Vernunft und demzufolge ein Recht auf Eigentum (iurisdictio) und Herrschaft (dominium). ${ }^{22}$ Nach unvoreingenommenen Beobachtungen kennen sie beide Institutionen: das Eigentum wie die Herrschaft (De Indis, I. 23). Vitoria besteht so auf dem gleichen Recht von Christen und Heiden, von Europäern und Indianern. Man darf weder indianische noch europäische Fürsten oder Einzelne (aut principes, aut privati) ihres Eigentums berauben. Als jura contraria sind diese Rechtstitel reversibel. Darum haben auch die Entdecker und Missionare natürliche Rechte in den »indischen« Territorien und gegenüber ihren

20 Carl Schmitt, Der Nomos der Erde im Völkerrecht des Jus Publicum Europaeum, Köln 1950, S. 71.

21 Vgl. dazu inzwischen von Wilfried Nippel, "Aristoteles und die Indios. >Gerechter Krieg < und `Sklaven von Natur < in der spanischen Diskussion des 16. Jahrhunderts «, in: Christoph Dippel und Martin Vogt (Hg.), Entdeckungen und frübe Kolonisation, Wiesbaden 1993, S. 69-90.

22 Neben Sepulveda, mit dem er der 2. Junta von Valladolid angehörte (1552) gilt Las Casas als Schrittmacher eines modernen Völkerrechts, vgl. Josef Bordat, Gerechtigkeit und Woblwollen. Das Völkerrechtskonzept des Bartolomé de Las Casas, Aachen 2006. 
Bewohnern. So steht ihnen z. B. das natürliche Recht auf Besuch und Umgang zu (naturalis societas et communicatio). ${ }^{23}$

Während Kant das Besuchsrecht der Entdecker und Händler später unter dem restriktiv verstandenen Grundsatz der Hospitalität aufnehmen wird ${ }^{24}$, behandelt Vitoria das Besuchsrecht seiner Landsleute in der für sie neuen Welt expansiv. Es bedeutet ihm - ausgehend vom Missionsauftrag - das Zutrittsrecht der Missionare, Entdecker, Händler, Kolonisatoren - mit Carl Schmitt zu reden: das »Recht der europäischen Landnahme im ganzen $\ll^{25}$. Kein Wunder, dass der Missionsauftrag, den der spanische König vom Papst für die neue Welt erhalten hat, eine tragende Rolle spielt; und da kriegerische Konflikte nicht nur zwischen den Neuankömmlingen und den Ureinwohnern, sondern auch zwischen den zum christlichen Glauben bekehrten und den bei den alten Göttern verbliebenen Ureinwohnern aufbrechen, muss Vitoria im Rahmen seiner Methode mit diesen Konflikten umgehen. Er tut dies nach der scholastischen Prüfung der Rechtsgründe, die auch für europäische Kriegsparteien maßgeblich ist: nämlich die Kasuistik von Rechtfertigungen (iusta causa belli, in: De Indis, III). Von ihr handelt die anschließende Relectio: De jure belli hispanorum in barbaros aus demselben Jahr 1539.

Die Führung von Kriegen - sei es in Europa oder in den »indischen " Gebieten steht in der Kompetenz weltlicher Fürsten (potestas civilis) und bedarf - anders als der Missionsauftrag und die damit verbundene Landnahme - keiner Mandatierung durch Kaiser oder Papst. Als das natürliche Recht der Staaten wird der Krieg bis ins 20. Jahrhundert hinein nicht in erster Linie nach Angriff und Verteidigung, sondern nach seinem Zweck und unter Rücksicht auf die Verhältnismäßigkeit von Zweck und Mittel beurteilt. Kriege sind gerechtfertigt, wenn es ihr Zweck ist, geraubtes Eigentum dem Eigentümer zurückzuerstatten und mit Strafe zu vergelten, wo Missetaten geschehen sind. »Denn wenn die Barbaren den Spaniern erlauben würden, friedlich mit ihnen Handel zu treiben, so könnten die Spanier von diesem Gesichtspunkt aus ihnen gegenüber mit keinem größeren Recht einen gerechten Grund zur Besitznahme ihrer Güter in Anspruch nehmen als gegenüber Christen « (De Indis, III Nr. 8).

Die Eroberung selbst wird nicht als Zweck, sondern als notwendige Folge anerkannt. Ein Fürst, der Krieg führt, um Eroberungen zu machen, kann dafür keinen zureichenden sittlichen Grund vorbringen (Non est iusta causa belli amplificatio imperii, in: De Jure Belli, Nr. 11), schon gar nicht, wenn er vor allem die Mehrung seines Ruhms oder seinen persönlichen Vorteil im Auge hat (gloria propria aut alind commodum principis, De Jure Belli, Nr. 12). Ein rechtfertigender Kriegsgrund muss am Gemeinwohl Maß nehmen (bonum commune ebd.); davon abgeleitet gelten als

23 Daraus folgt das »ius peregrinandi in illas provincias et illic degendi«, Vitoria, De Indis, III.2.

24 Dritter Definitivartikel des Ewigen Friedens, Immanuel Kant, Kleinere Schriften zur Geschichtsphilosophie, Ethik und Politik, hg. Karl Vorländer (Philos. Bibliothek Bd. 47), Hamburg 1973, S. $135 \mathrm{ff}$.

25 Carl Schmitt, Der Nomos der Erde (FN 20) S. 70. 
rechtfertigende Gründe: Eigentum verteidigen, geraubtes Eigentum zurückholen, aufgewandte Kriegskosten eintreiben, Missetäter im Interesse des Erdkreises bestrafen (necessaria ad gubernationem et conservationem orbis, De Jure Belli, Nr. 19) und die Kriegsgegner friedensgeeignet machen, d. h. sie beschämen, schwächen, unter Aufsicht stellen (necessaria ad defensionem boni publici, ad consequendam pacem et securitatem; Der Jure Belli, Nr. 15). Bestehen Zweifel, ob tatsächlich ein gerechtfertigter Grund zum Krieg vorliegt, dann ist ein Angriff verboten: »Im Zweifelsfall darf man den Besitzer nicht berauben « (De Jure Belli Nr. 27).

Nichts davon ist neu außer der Tatsache, dass ein innerhalb der Moraltheologie für die europäische respublica christiana entwickeltes Rechtfertigungs-Schema auch für den Krieg in der neuen Welt zwischen Christen und Nichtchristen zur Anwendung gebracht wird. Allerdings bleibt außerhalb der Klammer der Reversibilität und der Reziprozität, was das Besuchsrecht (naturalis communicatio) autoritativ veranlasst: das päpstliche Mandat an den spanischen König zur Heidenmission durch christliche Orden. Die in der Folge dieses Mandats entstehenden Verwicklungen lösen in der Form der Conquista Kriege aus, die nicht wegen des Eroberungszwecks, wohl aber im Rahmen der Heidenmission bzw. der Verteidigung der jungen Christengemeinden gerechtfertigt sein können. ${ }^{26}$

\section{Montesquieu}

Was Krieg zur Politik beiträgt, wie er eine Stadt zu einem Weltreich erweitert, das hat Montesquieu in seinen Studien zur römischen Geschichte ${ }^{27}$ breit erörtert und in den Reflexionen über die Universalmonarchie $\left(\mathrm{RMU}^{28}\right)$ variiert. In seinem Hauptwerk Vom Geist der Gesetze" (=Edl, 1748) und in Mes Pensées ${ }^{29}$ führt er aus, wie sich politische Regierungsformen zur Kriegsführung, speziell zum Eroberungskrieg, verhalten ( $E d l$, Buch X).

26 In diesem Sinn auch Carl Schmitt, wenn er schreibt: »Es kommt hier nicht darauf an, alle in Betracht kommenden >legitimen Rechtstitel der Spanier, die Vitoria darlegt, im einzelnen zu erörtern. Daß aber ihr Ergebnis schließlich doch zu einer Rechtfertigung der spanischen Conquista führt, hat seinen eigentlichen Grund darin, daß er den Unterschied von Christgläubigen und Nicht-Christen [nicht ]wirklich ignoriert und als nichtexistent betrachtet. Im Gegenteil: das praktische Ergebnis ist ganz in der christlichen Überzeugung Vitorias begründet«, Nomos der Erde (FN 4), S. 83.

27 "Considérations sur les causes de la grandeur des Romains et de leur decadence« (1734), in: Montesquieu, Oeuvres completès, hg. von R. Caillois, Bd. II (Pléjade), Paris 1951, S. 69-209.

28 »Réflexions sur la Monarchie Universelle en Europe«(1734), in: Montesquieu, Oewvres complètes II, S. 19-38.

29 »Mes Pensées V., Conquêtes et Traités«, in: Montesquieu, Oewores complètes II, 1951, S. $1426-1428$.

ZfP 55. Jg. 4/2008 
Im Rückblick auf seine »Römer«, deren kontinuierliche Eroberungspolitik er eingehend analysiert und in ihrer Singularität zu erklären versucht, ${ }^{30}$ zieht Montesquieu die uns heute voreilig erscheinende Bilanz, dass eine solche Kriegspolitik heute chancenlos geworden sei (»la guerre continuelle est destructive aujourd'hui«). Eine militärische Supermacht (»une superiorité constante sur les autres"), wie Rom es zu seiner Zeit gewesen sei, sei nicht mehr möglich. Die moderne Industrie und Technik habe nämlich die Kräfte der Individuen und die Macht der Staaten nivelliert, und auf dem Meer wirke sich die Erfindung des Kreiselkompasses mäßigend aus. ${ }^{31}$

Die hier angestellte Überlegung wird in den Reflexionen über die Universalmonarchie weiter entfaltet: Für deren wachsende Unwahrscheinlichkeit sprechen der Faktor Technologie, das Völkerrecht und der Handel (Holland erwirbt mehr über seine Kaufleute als über seine Soldaten). Die größte Macht stamme nicht aus Eroberungskriegen, sondern aus dem gemeinsamen Handel: Alle Kulturvölker seien die Mitglieder einer großen Republik geworden. Von Land zu Land seien variierende Reichtümer Grundlagen der Staatsmacht: »welchen Erfolg immer ein Eroberungsstaat haben könne, so gibt es immer eine gewisse Reaktion die ihn in den Zustand zurückkehren läßt, aus dem er ausbrach« (RMU Nr. II). Was Europa in den letzten 400 Jahren verändert habe, seien nicht die Kriege, sondern die Heiraten, die Thronfolgen, die Verträge, die Gesetze. »Es sind endlich rechtliche Vorkehrungen, wodurch Europa sich verändert und sich verändert hat « (RMU Nr. III). Montesquieu hält Eroberungskriege nicht mehr für zielführend, da sich in einem zusammenwachsenden Europa $a^{32}$ das Schicksal der Staaten eng miteinander verbunden habe und im ganzen immer neu ein Gleichgewicht der Mächte entstehe.

Auch im Geist der Gesetze bzw. in den Pensées reflektiert Montesquieu über kriegerische Eroberungen und Annexionen. Am wichtigsten hier seine Unterscheidungen nach der Intensität, in der die verschiedenen Regierungsformen (Republiken, Monarchien, Despotien) eine gewaltbereite Außenpolitik führen. ${ }^{33}$ Am »Eroberungsstaat « (Etat conquérant) zeigt er die Grenzen der Zweckmäßigkeit militärisch begründeter Staatsmacht (force de l'Etat): Generäle auf Eroberungskurs können für den Souverän - wie das spätrömische Beispiel zeigt - zu Konkurrenten

30 Über den beschränkten Gesichtspunkt seiner Analyse, die die zivilisatorische Mission ausblendet und nur »une machine concue par la conquête« beschreibt, handelt der Aufsatz von Paul Rahe, »Le live qui ne vit jamais le jour: les Considérations sur les Romains de Montesquieu et leur contexte historique «, in: Revue Montesquieu Nr. 8 , Librairie Droz S.A. 2005/06, S. 67-79.

31 »Dossier des Considérations Nr. 180 a-c, Chapitre IV «, in: Montesquieu, Oeuvres complètes II, hg. v. R. Caillois, (Pléjade), Paris 1951, S. 223.

32 "L'Europe n'est plus qu'une Nation composée de plusieurs... et l'Etat qui croit augmenter sa puissance par la ruine de calui qui le touche, s'affoiblit ordinairement avec lui." (RMU Nr. XVIII, Oeuvres complètes II, 1951, S. 34)

33 Marcel, Pekarek, Absolutismus als Kriegsursache: Die französische Aufklärung zu Krieg und Frieden (= Schriftenreihe Theologie und Frieden), Stuttgart u.a. 1997; PaulLudwig Weinacht, Montesquieus Interesse am Staat. Begriffsgeschichtliche Studien zu Regierungs- und Staatstypen im Esprit des lois, in: ZfP 47. Jg. NF4/2000, S. 446-457. 
werden ${ }^{34}$, und Eroberungspolitik - wie man am französischen Sonnenkönig sah $\mathrm{zu}$ anhaltender Erschöpfung des Staatsschatzes. An die ökonomischen Folgelasten der Kriegsführung wird 1784 auch Immanuel Kant erinnern, wenn er sagt, dass der Krieg die beteiligten Staaten »in einer immer anwachsenden Schuldenlast (einer neuen Erfindung) « halte. ${ }^{35}$ Von dieser Erfahrung her wird der Fall Dünkirchens vorbildhaft, wo der König sich nicht wie an anderen festen Orten zu aufwändiger Belagerung entschloss, sondern die Stadt zu einem vernünftigen Preis kaufte. ${ }^{36}$ Militärische Interventionen lassen sich durch kluge Politik überflüssig machen. So sei es ein politischer Fehler, sich schwächere Nachbarn einzuverleiben, wenn man erkannt hat, dass es nicht auf die »absolute Macht « eines Staats, sondern auf seine »relative Macht « ankomme, nämlich auf seine Machtstellung im Verhältnis zu den Nachbarn (»relative Macht«). Frankreich habe zur Zeit des Sonnenkönigs keinen Nachbarstaat zu fürchten gehabt, da alle unorganisiert und schwach waren. Aber Ludwig habe die relative Machtstellung verspielt, weil er nicht begriff, dass es für einen Fürsten nichts Bequemeres gebe als Nachbarn zu haben, die gezwungen seien, wegen der inneren Zerrüttung ihrer Macht alle Schicksalsschläge (tous les outrages de la fortune) hinzunehmen. »Und es ist selten, daß durch die Eroberung eines vergleichbaren Staates soviel reale Macht dazukommt wie relative Macht verloren geht.«(Edl IX.10. Eine fast machiavellisch zu nennende Erwägung!)

War diese Überlegung - unter der Überschrift von der »Verteidigungskraft eines Staates « (Edl IX.) noch realpolitischer Natur, so folgen unter der Überschrift von der »Angriffsstärke« (Edl X) rechtliche Erwägungen; Angriffsstärke werde nämlich »durch das Völkerrecht geregelt «.37 Das Völkerrecht zur Zeit Montesquieus ist aber nicht mehr dasjenige Vitorias. Naturrechtliche Erwägungen gehen jetzt ganz und gar vom Recht der Selbsterhaltung aus. Die natürliche Legitimation des Rechtes zum Krieg im zwischenstaatlichen Bereich sei - so wie die Notwehr des Individuums unter Staatsgesetzen - die Selbsterhaltung des Staates. Dieses Prinzip gelte zwar der Verteidigung, decke im zwischenstaatlichen Bereich aber auch den Fall des Angriffs ab, der nur durch Selbsterhaltung zu rechtfertigen sei. Das ist der Fall, wenn Angriff »n diesem Augenblick das einzige Mittel ist, diese Vernichtung zu verhindern«. Als vorwegnehmende Verteidigung kommt der Angriff vor allem den kleinen Staaten zu, die Grund haben sich zu fürchten, nicht den großen Reichen. Das Recht zum Krieg leitet sich nämlich aus der Notwendigkeit (nécessité) und aus dem Recht im eigentlichen Sinn (le juste droit) ab. Es gibt freilich Räte (»welche das Gewissen oder die

34 »Conquêtes et Traités Nr. 1776-1778«, in: Montesquieu, Oeuvres complètes I, S. 1426.

35 Immanuel Kant, Idee zu einer allgemeinen Geschichte in weltbürgerlicher Absicht (1784), Philosophische Bibliothek Bd. 471, S. 14 f.

36 »Louis XIV acheta Dunkerque 4 millions. Il n'a guère assiégé de places qu'il ait eues à meilleur marché", Pensée Nr. 1614, in : Montesquieu, CEuvres Complètes, ed. Roger Caillois, Bd. 1, Paris (Gallimard) 1949, S. 1390. Wo nicht anders zitiert, wird der Esprit des lois (Edl) im folgenden durchweg nach der Ausgabe von Caillois zitiert.

37 Zur Unterscheidung vom Rechten und Nützlichen in Auseinandersetzung mit Grotius vgl. Jean Terrel, A propos de la conquête: droit et politique chez Montesquieu, in: Revue Montesquieu Nr. 8, Librairie Droz S.A. 2005-2006, S. 137-150. 
Entschlüsse der Fürsten lenken «, man denkt unmittelbar an Machiavelli), die eher auf des Fürsten Ruhm, Tadellosigkeit (bienséance) oder Nutzen sehen, als auf Recht - ihre Gewaltpolitik überschwemme die Erde mit Strömen von Blut. Montesquieu benutzt hier eine Wendung wie im Gewaltenteilungskapitel, wo sie den völligen Verlust der Freiheit bezeichnet: »alles ist verloren« (tout est perdu, Edl X.2, vgl. Edl XI.6). Mit Vitoria formuliert er: Ein für den Ruhm des Fürsten geführter Krieg hat kein legitimes Recht auf seiner Seite, denn Ruhm ist Stolz und also eine Leidenschaft. Und wenn schon die fürstliche Reputation die Staatsmacht erhöht, würde gleiches nicht auch vom Ruf der Gerechtigkeit gelten? Durch Rückgriff auf das jus gentium der Schule von Salamanca relativiert Montesquieu das Machtstaatsdenken seiner Epoche und öffnet einen alternativen Weg in Richtung auf den Rechtsstaat.

Aus dem Recht zum Krieg entspringt das Recht der Eroberung als seine Folge auch dies ein Gedanke, der sich bei Vitoria findet. Montesquieu benutzt ihn jedoch invers: die Eroberungsfolge müsse auf den Geist zurückwirken (suivre l'esprit), in dem der Krieg geführt wird, nämlich nicht durch verbrannte Erde, sondern nach dem Naturgesetz (Streben nach Arterhaltung), nach natürlicher Vernunft (goldene Regel), nach dem für jede Staatsgründung geltenden Gesetz der Dauer (Staaten sterben nicht) und nach der Natur der Sache (Eroberung sei eine Erwerbs-, keine Zerstörungsform). Annexionen ließen sich verwalten, indem 1. die alten Gesetze in Kraft bleiben und der neue Landesherr sie nur von seinen eigenen Leuten administrieren läßt, 2. eine komplett neue Staats- und Zivilverwaltung eingerichtet wird, 3. die Dismembration der Gesellschaft und ihre Zerstreuung auf andere Staaten beschlossen wird, 4. alle Bürger ausgerottet werden. Die erste Umgangsweise entspreche dem heutigen Völkerrecht (que nous suivons aujourd'bui), die letzte den archaischen Sitten der Römer.

Wenn Staatsrechtler aus dem Grundsatz, daß der Eroberer den eroberten Staatsverband zerstören dürfe, den Schluss ziehe, dass der Eroberer auch die unterworfenen Menschen vernichten oder zu Sklaven machen dürfe, dann irrt er. Zerstörungen freilich sind erlaubt, solange sie zur Sicherung der Eroberung unabdingbar sind. Wieviel Gutes hätten die Spanier den Mexikanern tun können: Sie hätten »die Sklaven befreien können, aber sie machten die Freien zu Sklaven. Sie konnten sie über den Mißbrauch der Menschenopfer aufklären, stattdessen rotteten sie sie aus.«(Edl X.4). In aufklärerischem Geist definiert er »Eroberung « als »ein notwendiges, legitimes und unglückseliges Recht, das immer eine unendlich große Schuld zurückläßt, die man abgelten muss, um gegenüber der menschlichen Natur quitt zu werden«. (Die »menschliche Natur«, die hier als Maß genannt ist, würden wir heute mit der »Menschenwürde« identifizieren. ${ }^{38}$ )

38 Forsthoff übersetzt: »um sich vor der Menschheit von ihr zu befreien«, was den Sinn nicht ganz trifft. Denn es geht hier nicht um das Kollektiv aller Menschen, sondern um die konkret-abstrakte menschliche Natur. Anders liegt der Fall, wo Menschheit Menschengeschlecht meint (»genre bumain «), zu dessen »Nutzen« die Syrakusaner die Karthager genötigt hätten, von den Kindstötungen in ihrer Stadt abzulassen (vgl. Edl X.4, X.5), siehe Montesquieu, Vom Geist der Gesetze Bd.1, übersetzt und herausgegeben von Ernst Forsthoff, Tübingen 2. Auf. 1992 (= UTB Bd.1710), S. $195 f$. 
Montesquieu kennt zwei differente Grundsätze: einen militärischen für das Erobern und einen zivilen für die Nutzung des eroberten Gebiets. Im Sinn seines Mäßigungs-Prinzips empfiehlt er dem Eroberer, den Eroberten sowohl die eigenen Gesetze, vor allem aber die eigenen Sitten (wenn sie menschlich sind) und das damit einhergehende Ehrgefühl zu lassen (Edl X.11 f.). Im Licht dieses Prinzips nennt er die großen und raschen Eroberungen mehr das Werk der Wildheit als der Klugheit und daher mehr eine Sache von Abenteurern als von großen Monarchen. ${ }^{39}$ Die Kapitel über den Handel zeigen, wie er sich die Beziehungen Europas nach Übersee vorstellt, nämlich so, wie sie von den Engländern gepflegt werden. Sie bilden das Gegenbild zu den Spaniern, denen er unterstellt, sie hätten den Unterschied der Grundsätze von Eroberung und Nutzung der in Südamerika eroberten Gebiete nie vollzogen. Handel (le doux commerce) ist für Montesquieu die zivilisatorisch überlegene Form der Nutzung kolonialer Eroberungen (l'empire de la mer). ${ }^{40}$

\section{Immanuel Kant}

Kants historisch-politische Kriegsanalysen kulminieren in den Präliminarien seiner berühmten Friedensschrift aus dem Jahr 1795. Erstmals hat er sich 1784 mit dem Thema auseinandergesetzt, nämlich in der Vorlesung Idee zu einer allgemeinen Geschichte in weltbürgerlicher Absicht und in der Rechtsphilosophie von 1797 die in der Friedensschrift geklärten Prinzipien reformuliert.

Kant hat Krieg zunächst anthropologisch und geschichtsphilosophisch interpretiert: »ein unvermeidlicher Antagonismus«, der aus der »Unvertragsamkeit der Menschen, selbst der großen Gesellschaften und Staatskörper « resultiere und der ein Mittel sei, mit dem die Natur »einen Zustand der Ruhe und Sicherheit auszufinden « versuche. Subjekt ist hier die Natur, die den Menschen als Gattungswesen zum Objekt ihrer Zwecke benutzt. Die menschliche Vernunft freilich brauche »soviel traurige Erfahrung " gar nicht, um an deren Ende ermattet und ernüchtert das Richtige zu tun: nämlich »aus dem gesetzlosen Zustande der Wilden hinauszugehen und in einen Völkerbund zu treten $«$ - einen »Foedus Amphictyonum «. ${ }^{41}$ Freilich ist die Vernunft (noch) schwach angesichts des alles überschattenden hobbes'schen Grundmisstrauens. Kant wird jedoch kein Misanthrop, denn wenn wir vom Krieg ständig in Atem gehalten werden, so hat dies auch seine gute Seite: nämlich dass wir schließlich zu einem »weltbürgerlichen Zustand der öffentlichen Staatssicherheit « kommen, die im Blick auf die »Freiheit « der Staaten vom »Gesetz des Gleichgewichts « zu erwarten sei..$^{42}$ Ein solcher Zustand der Staatensicherheit bedeutete nicht nur ein Ende kriegerischer Ge-

39 »Conquêtes et Traités « Nr. 1775 in Montesquieu, Oeuvres complètes II, S. 1426

40 Marco Platania, »Dynamiques des empires et dynamiques du commerce: inflexions de la pensée de Montesquieu (1734 -1802)«, in: Revue Montesquieu Nr. 8, 2005/06, S. 43 66 (55 ff.) und Michael Mosher, »Montesquieu on Conquest: Three Cartesian Heroes and Five Good Enough Empires», in: ebd. S. 81-110.

41 I. Kant, Idee zu einer allgemeinen Geschichte in weltbürgerlicher Absicht (1784), in: Philosophische Bibliothek Bd. 171, S. $12 \mathrm{ff}$.

42 I. Kant, ebd. S. 14 f.

ZfP 55. Jg. 4/2008 
walt, der Kriegsrüstung und ihrer Folgen, sondern positiv: dass in einem solchen $\mathrm{Zu}$ stand »alle ursprünglichen Anlagen der Menschengattung entwickelt werden «. ${ }^{43}$

Die Naturgeschichte der Kriegsführung zeitigt aber nicht nur in »weltbürgerlicher «, sondern auch in staatsbürgerlicher Hinsicht ein Gut: das »unschätzbare Gut der Freiheit«. Die Potentaten können es sich nämlich nicht leisten, ihre Untertanen angesichts der Revolutionsschalmeien zu unterdrücken: »denn Kriegsgefahr ist auch noch jetzt das einzige, was den Despotismus mäßigt «44. (Ein warnendes Beispiel sollte die radikale Mainzer Bürgerschaft geben, als sie mit den französischen Jakobinern fraternisierte.)

Auch zivilisatorisch ist Krieg ein Gut, zumindest »auf der Stufe der Kultur...worauf das menschliche Geschlecht noch steht«: insofern nämlich, als er die Funktion eines »unentbehrlichen Mittels, diese [Kultur] noch weiter zu bringen «, erfülle, während ein immerwährender Friede, wenn er »heilsam « sein soll, nach einer »(Gott weiß wann) vollendeten Kultur « verlange. ${ }^{45}$

Die Frage also, ob wir es mit Krieg oder mit Frieden halten sollen, ist von näheren Umständen abhängig und im ganzen von ihrer Wirkung auf die Tugend eines Volkes ${ }^{46}$ und den Kulturfortschritt der Gattung ${ }^{47}$. Die Allgemeinheit der anthropologischen und kulturphilosophischen (»ästhetischen «) Betrachtungsweise Kants bestimmt vor den Arbeiten der Neunzigerjahre seinen Begriff des Krieges. Er sieht im Krieg noch nicht eine Niederlage der moralischen Vernunft, sondern eine Naturtatsache menschlicher »Unverträglichkeit « und ein Ereignis innerhalb des zwischen Staaten fortgeltenden hobbesianischen status juridicus (naturalis) ${ }^{48}$.

Erst in der Moral- und Rechtsphilosophie, also in der Abhandlung über den Gemeinspruch (1793), den philosophischen Entwurf über den Ewigen Frieden (1795) und die Rechtslebre (1797) tritt an die Stelle der Rechtfertigung aus dem Naturzweck die Rechtfertigung aus dem Recht, womit der Angriffs- und Eroberungskrieg, ja Krieg und Annexionen überhaupt in die Kritik geraten. ${ }^{49}$

43 I. Kant, Idee zu einer allgemeinen Geschichte, S. 17 f.

44 I. Kant, Mutmaßlicher Anfang der Menschengeschichte (1786), in: Philosophische Bibliothek Bd. 471, S. $60 \mathrm{f}$.

45 I. Kant, ebd., S. 62.

46 In seiner Kritik der Urteilskraft (1790) preist Kant den völkerrechtlich gehegten Krieg: »Selbst der Krieg, wenn er mit Ordnung und Heiligachtung der bürgerlichen Rechte geführt wird, hat etwas Erhabenes an sich...dagegen ein langer Frieden den bloßen Handelsgeist, mit ihm aber den niedrigen Eigennutz, Feigheit und Weichlichkeit herrschend zu machen und die Denkungsart des Volks zu erniedrigen pflegt.«I. Kant, Kritik der Urteilskraft (1790), Philosophische Bibliothek Bd. 39, S. 109.

47 Krieg: »eine Triebfeder mehr...alle Talente, die zur Kultur dienen, bis zum höchsten Grade zu entwickeln«, I. Kant, Kritik der Urteilskraft (1790), Philosophische Bibliothek Bd. 39, S. 302.

48 I. Kant, Die Religion innerbalb der Grenzen der bloßen Vernunft (1793), in: Philosophische Bibliothek Bd. 45, S. 110 f. Anm.

49 Sämtliche Texte zu Krieg und Frieden bei Kant hat Karl Vorländer zusammengetragen in: Immanuel Kant, Zum ewigen Frieden. Mit Ergänzungen aus Kants übrigen Schriften und einer ausfübrlichen Einleitung über die Entwicklung des Friedensgedankens herausgegeben von Karl Vorländer, Leipzig, 2. Auflage 1919, S. 56-74. 
Jetzt wird der ewige Friede zum »letzten Ziel des ganzen Völkerrechts« und eine »auf die Pflicht, mithin auch auf dem Rechte der Menschen und Staaten gegründete Aufgabe.$^{50}$ Das Recht zur Kriegsführung ist für Kant kein Recht des Souveräns auf Verpflichtung seiner Untertanen, sondern im Gegenteil: Es ist von einer Pflicht des Souveräns gegen das Volk abzuleiten, also im Grundsatz zustimmungspflichtig durch dessen Repräsentanten. ${ }^{51}$ Völkerrechtlich betrachtet, ist Krieg ein unvermeidliches Ereignis in einem Zustand allgemeiner Hostilität, wo Rechtsverfolgung »durch eigene Gewalt « geschieht. Diese Art Rechtsverfolgung hat ihren Ort da, wo ein Staat sich durch einen andern »lädiert glaubt « (»tätige Verletzung«, »erste Aggression «) oder wo er sich von einem oder mehreren anderen bedroht fühlt (durch »vorgekommene Zurüstung«, »durch Ländererwerbung anwachsende Macht«). Der Grundsatz inter arma leges silent mache es freilich schwer, Krieg nach Maßgabe eines Gesetzes als rechtens anzusehen, und also muss man sich auf die Forderung beschränken, dass es »noch möglich bleibt, aus jenem Naturzustande der Staaten (im äußeren Verhältnis gegeneinander) herauszugehen und in einen rechtlichen zu treten.«Eroberungskrieg sei im Übrigen selbst dort ein völkerrechtswidriges »Notmittel des Staats «, wo er dazu dient, »zum Friedenszustande zu gelangen $\ll^{52}$.

Kriegerischen Eroberungen unterliegen nach dem Völkerrecht festen Unterscheidungen hinsichtlich des Status des Landes und desjenigen seiner Einwohner. Der »überwundene Staat« könne nicht »Kolonie« werden, da eine Kolonie sich zwar als »Tochterstaat« noch regieren könne, vom souveränen »Mutterstaat« aber beherrscht werde. Auch verlieren die Untertanen des eroberten Staats nicht ihre »staatsbürgerliche Freiheit«, um in Leibeigenschaft zu geraten, denn zu derlei bedürfte es eines »Strafkrieges «, der zwischen gleichberechtigten Staaten ja gerade nicht stattfinden kann. ${ }^{53}$

Am Beispiel der feudalen Besitzverschiebungen (Erbung, Tausch, Kauf oder Schenkung) diskutiert Kant im Traktat vom Ewigen Frieden (1775) die Bedingungen für rechtlich zulässige Annexion von Gebieten und ihrer Bevölkerung (1. Präliminarartikel). Das Prinzip der Zulässigkeit ist die Anerkennung der Subjektstellung von Land und Leuten als politisch geeinter Gesellschaft. Demnach hat ein Staat einen Regenten, nicht umgekehrt, gar im Sinn von Eigentum. Ein Staat nämlich, so Kants Grundsatz, ist keine Habe (patrimonium): »Er ist eine Gesellschaft von Menschen, über die niemand anders als er selbst zu gebieten und zu disponieren hat. Ihn aber, der selbst als Stamm seine eigene Wurzel hatte, als Pfopfreis einem andern Staate einzuverleiben, heißt seine Existenz als einer moralischen Person aufheben und aus der letzteren eine Sache machen, widerspricht also der Idee des ursprünglichen Vertrags, ohne die sich kein Recht über ein Volk denken läßt.« «4 Damit ist ein auf Eroberung im Sinne von Erwerb (vgl. Montesquieu) gerichteter Krieg im Grundsatz sitten- und rechtswidrig.

50 I. Kant, Rechtslehre $\$ 61$ (1797), Philosophische Bibliothek Bd.42, S.175 ff.

51 Rechtslehre ebd., $\$ 55$.

52 Rechtslehre ebd., $\$ 57$.

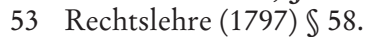

54 I. Kant, Ewiger Friede, hg. v. K. Vorländer, Leipzig 1919, S. 5. 
Am Beispiel des Interventionskriegs der europäischen Mächte gegen das revolutionäre Frankreich diskutiert Kant die Problematik des politischen »Interventionskrieges « (5. Präliminarartikel). Zwei Argumente werden vorgeführt: der angebliche Skandal eines schlechten Beispiels eines anderen Staates auf die eigenen Untertanen und die solidarische Hilfeleistung für die Partei des besseren Rechts im Bürgerkrieg. Das eine wie das andere seien keine berechtigten Interventionsgründe: das erste nicht, weil ein scandalum acceptum keine Läsion für eine moralische Person darstelle, und das zweite nicht, weil dadurch die Autonomie aller Staaten unsicher gemacht würde. ${ }^{55}$

Am Beispiel der Kolonialerwerbung in Amerika, den »Negerländern«, den Gewürzinseln, dem Kap usw. stellt Kant den vermeintlichen Grund der Entdeckung und des Besuchs fremder Länder und Völker ${ }^{56}$ als Vorwand für Eroberungskriege bloß - und das bei »Mächten, die von der Frömmigkeit viel Werks machen, und, indem sie Unrecht wie Wasser trinken, sich in der Rechtgläubigkeit für Auserwählte gehalten wissen wollen ${ }^{57}$.

\section{Meinungskampf im Zeitalter der Massenmedien (Kriegspropaganda)}

Der moral- und rechtsphilosophische Friedensdiskurs mit Kant und die zivilisatorische Verurteilung des Angriffskrieges durch Benjamin Constant haben der »Hegung des Krieges« (C. Schmitt) Gewicht gegeben, das Kriegführen selbst aber aus der Staatenpraxis des 19. und 20. Jahrhunderts ebensowenig verdrängen können wie die zeitgenössische pazifistische Literatur. Im Gegenteil: ergänzend zur Kriegsführung auf den realen Schlachtfeldern entstand eine Kriegsführung der Buchstaben und Bilder, sozusagen ein Kriegsschauplatz für Ideen, dessen Bedeutung im Verlauf des Krieges 1914/1918 immer stärker gesehen wurde. ${ }^{58}$ Wir beziehen uns nachfol-

55 I. Kant, Ewiger Friede, hg. K. Vorländer, Leipzig 1919, S. 7.

56 »welches ihnen mit dem Erobern derselben für einerlei gilt«, I. Kant, Ewiger Friede, S. 24.

57 I. Kant, ebd., S. 23 f.

58 Auch wenn amtliche Propaganda sich mit der in den Stäben gesammelten Kriegsberichterstattung und journalistischen Berichten und Kommentaren teilweise deckt, so will sie teils im Innern, teils gegenüber Neutralen psychologische und politische Wirkung entfalten. Dazu allgemein: Thymian Bussemer, Konzepte und Theorien, Wiesbaden 2005. Zur Entwicklungsgeschichte: Ute Daniel, Wolfram Siemann, »Historische Dimensionen der Propaganda «, in: Dies. (Hg)., Propaganda, Meinungskampf, Verführung und politische Sinnstiftung (1789-1989), Frankfurt 1994, S. 7 ff.; zur Entwicklungsgeschichte der Kriegspropaganda auch Hinweise bei Herfried Münkler, Über den Krieg, Weilerswist 2002, S.189 ff.. Vgl. zur unterschiedlichen Kriegspropaganda von Entente-Mächten und Deutschem Reich im Ersten Weltkrieg: Lebendiges Virtuelles Museum online, das vom Haus der Geschichte der Bundesrepublik und vom Deutschen Historischen Museum ins Internet gestellt wird (www.dhm.de/lemo/ htm/ wk1/index.html.); zu aktuellen Propagandaformen Frank Schumacher, Kalter Krieg und Propaganda. Die USA, der Kampf um die Weltmeinung und die ideelle Westbindung der Bundesrepublik Deutschland, 1945 - 1955, Trier 1997; Thomas Knieper, Marion G. Müller (Hg.), War Visions. Bildkommunikation und Krieg, Köln 2005, S. 120-152; Linda Hentschel (Hg.), Bilderpolitik in Zeiten von Krieg und Terror: Medien, Macht und Geschlechterverhältnisse, Berlin 2008. 
gend beispielhaft auf die Erinnerungen des Zentrumsabgeordneten Mathias Erzberger, der von Reichskanzler v. Bethmann-Hollweg im Jahr 1914 als Leiter einer "Zentralstelle für Auslandsdienst « berufen worden war, um während des Krieges für die Reichsregierung - allerdings im Rahmen der Zensur der Oberste Heeresleitung planvoll auf die öffentliche Meinung im neutralen Ausland einzuwirken. Es war das erstemal, daß auf Reichsebene in Deutschland eine solche Stelle errichtet wurde.

Erzbergers 1920 publizierten Erlebnisse im Weltkrieg ${ }^{59}$ beginnen mit einem Kapitel über »Propagandatätigkeit«, in dem er die politische Bedeutung dieser neuartigen Form kriegsbegleitender Information herausstreicht. Erzberger erinnert an den Balkankrieg, in dem »Bulgarien der Welt gezeigt hatte, daß es nicht nur darauf ankommt, Schlachten zu schlagen und zu gewinnen, sondern auch die öffentliche Meinung der nicht kämpfenden Welt für sich zu erobern«. Er sieht, dass Kriege, in denen es auch um Annexion geht bzw. deren Beteiligten dieses Interesse unterstellt wird, leichter gewonnen werden, wenn das Urteil des neutralen Auslands gewonnen wird. Denn die Sympathie der Völkergemeinschaft erleichtert und ihre Akzeptanz vollendet den Sieg.

Diese neue Gesetzmäßigkeit hatte, nach Erzbergers Überzeugung, die Oberste Heeresleitung im Sommer 1914 auf die leichte Schulter genommen. Anders als England, wo man schon im ersten Kriegsjahr ein »War Propaganda Bureau " gebildet hatte, nahm man in Deutschland »die mit einem modernen Krieg untrennbar verbundene Aufklärungsarbeit des In- und Auslandes « zu spät und unvollständig wahr. ${ }^{60}$ Sie kam gegen ein bereits in den ersten Kriegsmonaten verfertigtes Bild von den deutschen Truppen als »Barbaren « (»Hunnen«) nicht mehr an. Und vor allem: »Wie sehr der deutsche Einmarsch in Belgien uns politisch geschadet hat, wurde mir so recht klar bei meinen häufigen Aufenthalten im neutralen Ausland...In Deutschland selbst wurde die öffentliche Meinung noch mehr erregt durch die Meldungen über den Franktireurkrieg. «61 Das neutrale Ausland indes sah den Kriegsverlauf durch eine Brille, die von der antideutschen Propaganda der Ententemächten zur Besichtigung angeblicher deutscher Kriegsverbrechen und immer wieder der belgischen Frage wieder und wieder zugeschliffen wurde. Erzberger klagt, dass die maßgebenden deutschen Militärs »die Psychologie des Krieges bis zu seinem schrecklichen Ende nicht erfaßt « hätten: »Die deutsche Propaganda durfte unter dem Druck militärischer Stellen kein Gegengewicht schaffen. Der Einfall in Belgien brachte nahezu die ganze Welt gegen Deutschland auf. Belgien wurde, wie ich im Reichstag sagte, >der Liebling der Welt. « ${ }^{62}$ Die Obersten Heeresleitung war für eine politisch wirkungsvolle Kriegführung nicht zu gewinnen. ${ }^{63}$

59 Mathias Erzberger, Erlebnisse im Weltkrieg, Stuttgart/Berlin 1920.

60 Erzberger, ebd., S. 2 f.

61 Erzberger, Erlebnisse (1920), S. 199.

62 Erzberger ebd. S. 8.

63 Erzberger ebd. S. 314 «Als Politiker erklärte ich den amtlichen Stellen wiederholt, daß unsere gesamte Kriegführung zu wenig politisch sei. Ich verstand weder das Blutvergießen bei Ypern Ende 1914 noch den Riesenansturm auf Verdun 1916, hielt es vielmehr für richtiger, im Herbst 1915 die ganze Kraft weiter nach dem Osten zu werfen, um durch den Einmarsch in die Ukraine die Ernährung Deutschlands zu sichern«. 
Gegen Völkerrecht verstieß nicht der Angriffskrieg als solcher, sondern die Gebietsverletzung eines neutralen Staates, die der Propaganda der Westmächte rechtliche und psychologische Vorteile eintrug. ${ }^{64}$ Erzbergers Bemühungen in der Zentralstelle zielten darauf ab, dieses Handicap deutscher Politik zu relativieren. So ließ er etwa katholische deutsche Parlamentarier am 2. September 1914 eine Denkschrift an die in Rom bei einem Konklave weilenden Kardinäle überreichen, um dem katholischen Europa zu sagen, das deutsche Volk habe sich in den Tagen der Prüfung als ein glaubensstarkes Volk erwiesen, »daß es aber einem Feind machtlos gegenüberstehe: der Lüge. Deutschland führt den Krieg nicht aus Eroberungslust, sondern es kämpft um seine Existenz...Dem Katholizismus in ganz Westeuropa tritt kein gefährlicherer Feind entgegen als der gewalttätige Russe, der seit Jahrhunderten die polnischen Katholiken mit den brutalen Mitteln der Gewalt von der Kirche gerissen hat $\ll^{65}$.

Dieses Memorandum hielt Erzberger darum für gelungen, weil es:

- das deutsche Volk als in einem »Existenzkampf« stehend beschrieb und nicht als von »Eroberungslust « getrieben, die seit Constant als Kriegsmotiv verfemt war;

- die Neutralen auf eine Gefahr aufmerksam machte, vor der ihr deutsche Siege Schutz gewähren könnten: das gewalttätige Zaren-Regime und die dem katholischen Europa drohende (russisch-orthodoxe) Religionspolitik.

Während der zweite Punkt ein gemeinsames Interesse zwischen Deutschland und Europa ins Spiel brachte, warb der erste um Wohlwollen unter den Liberalen Europas. Dessen ungeachtet löste das Memorandum erbitterte Reaktionen der französischen Bischöfe und Kardinäle aus.

Der psychologische Faktor des Wohlwollens war damals alles, was bei der Führung eines Angriffs- oder Revanchekrieg beachtet werden musste. Seit dem BriandKellogg-Pakt nahm die Kriegspropaganda ein andere Richtung: Von nun an galt es nicht nur, das Recht der Neutralen zu wahren, sondern zusätzlich als »Verteidiger « aufzutreten und die Gegenseite als Angreifer, das heißt: als Kriegsverursacher erscheinen zu lassen. Mit dem Verzicht auf das jus belli war der »Verteidigungskrieg « zur diplomatischen und propagandistischen Grundlage militärisch operierender Außenpolitik der Staaten geworden.

$64 \mathrm{Daß}$ auch die auf fremde Staaten zielende propagandistische Diffamierung der deutschen Soldaten als Bestien, Hunnen, Kriegsverbrecher durch die antideutsche Propaganda der Entente gegen Völkerrecht verstieß (Art. 22 Haager Landkriegsordnung), blieb merkwürdigerweise ungeahndet; die deutsche Seite enthielt sich vergleichbarer Diffamierung, vgl. dazu Weltkrieg 1, Kriegspropaganda, in: LeMO (www. dhm.de).

65 Erzberger ebd. S. 11. 


\section{Ergebnisse}

\section{Krieg}

Krieg ist für Machiavelli eine Weise von Fürsten und von Privatleuten, den Wettbewerb um Macht zu gewinnen. Als Mittel für Machtgewinn und Machtbehauptung ist der Krieg keine ultima ratio, sondern eine gängige Form von Politik, die man nur zu vermeiden sucht, wenn sie einem ungelegen kommt. Für Vitoria ist der Krieg ein Übel, aber in gewissen Fällen und in gewissem Umfang zu rechtfertigen etwa im Blick auf die Sicherung der Evangelisation unter den Indianern. Eroberungen an sich waren kein erlaubter Zweck. Ein Übel sind Kriege auch für Montesquieu, für den die unterschiedlichen Formen des Regierens kürzere oder längere Kriegsschatten werfen. Angriffskriege bleiben - außer in der Absicht der Verteidigung bzw. der Schwächung der Gegner ${ }^{66}$ - moralisch verwerflich. Im Ganzen herrscht die Vorstellung, dass mit fortschreitender Zivilisation Krieg unrentabel werde und Eroberungen sich nicht mehr rechnen. Kant sieht im Krieg zunächst eine Erscheinung des Naturzustandes, in dem Staaten untereinander ihr Recht suchen, und formuliert ein relatives Gute, das die Natur vermittels Gewalt und Leid der Menschen ins Werk zu setzen beginne; später wird ihm Krieg mehr und mehr zur Niederlage der Vernunft und des sittlichen Willens.

\section{Eroberungen}

Für Niccolo Machiavelli war Krieg der Königsweg zu Gründung und Erweiterung von Staaten Bei Machiavelli gehen Fürsten ihrer »Eroberungslust « nach, sie »ist etwas sehr Natürliches und Verbreitetes«. Bei Vitoria sind Eroberungen als Folgen, nicht aber als der Zweck eines Kriegs gerechtfertigt. Montesquieu hat Eroberungen als Ursache der äußeren Größe Roms analysiert und auf vielfältige mehr oder weniger singuläre Faktoren zurückgeführt. In der Gegenwart diskutiert er Eroberungen nicht mehr unter der Perspektive der Universalmonarchie, sondern utilitaristisch: Eroberungen dürften nicht mit verbrannter Erde gemacht werden, da diese Strategie dem Erwerbsprinzip widerspreche und den Wert des annektierten Gebiets mindere. Montesquieu beschäftigt sich in Der Geist der Gesetze mehr mit den Möglichkeiten der Verwaltung von Annexionen als mit den Weisen, Krieg zu führen. Die zivilisatorisch höchste Form, ein erobertes Gebiet zu verwalten, ist die, der Bevölkerung nach Möglichkeit ein Leben in Selbstbestimmung zu ermöglichen. Was für Montesquieu die höchste Stufe der Verwaltungen neu erworbenen Landes ist, ist für den Kant der Neunzigerjahre die rechtliche Bedingung von Annexion überhaupt. Land und Leute, gleichgültig ob erworben oder erobert, sind ihm keine Habe eines Staatsoberhaupts und keine Kolonie mit Leibeigenen eines Überwinders

66 Pensée Nr. 1532: »on ne cherchoit pas tant à s'agrandir qu’à affoiblir ses ennemis«, in: Montesquieu, Euvres Complètes, Bd. 1, Paris 1949, S. 1370.

ZfP 55. Jg. 4/2008 
(also weder Erwerb noch despotische Machterweiterung im Sinne Montesquieus), sondern moralische Personen, die Subjekt der Selbstbestimmung bleiben.

\section{Formen von Krieg und Annexion}

Machiavelli vertritt eine Naturlehre der Eroberung. Ihr perspektivisches Paradigma ist die erhoffte Befreiung Italiens von den Barbaren, die er von einem principe nuovo erwartet, der aus eigenen Staaten aufbricht und von der Bevölkerung in den eroberten Staaten als »Volksfürst « und Befreier begrüßt wird. Machiavelli appelliert an den Ehrgeiz italienischer Kleinfürsten, sich nicht im Streit um ihre jeweiligen Erblande zu verzetteln, sondern in der Wiedervereinigung des größeren italienischen Vaterlandes eine Lebensaufgabe zu suchen.

Vitoria argumentiert auf der Basis des Naturrechts, das zwischen Völkern unterschiedlicher Zivilisation und Religion reversible Ansprüche und Pflichten begründet. Danach gibt es für beide Seiten erlaubte und nicht erlaubte Kriegsgründe, die nicht obenhin, sondern mit Sorgfalt und durch unparteiische weise Männer zu prüfen sind (De Jure Belli Nr. 20 f.). Im Zweifel muss auf eine für rechtmäßig behauptete Eroberung verzichtet werden (»In dubiis melior est condicio possidentis. "De Jure Belli Nr. 27), denn sie würde zum Grund für einen »Rück «-Eroberungskrieg werden, und dadurch hörte der Krieg zum Verderben des Volkes niemals auf. Wo - wie durch die conquista - neue Eroberungen gemacht werden, lassen sich diese nur als Folge, nicht als Zweck rechtfertigen. Das positive Paradigma der vitorianischen Lehre ist nicht der intentionale, sondern der funktionale Eroberungskrieg in der Neuen Welt. Eroberungen sind dort Folge der naturalis communicatio, und sie sind als Konflikte gerechtfertigt, bei denen es um die Freiheit der Mission und den Schutz der Bekehrten geht. Intentional, das heißt nach dem Grundsatz der Machterweiterung der spanischen Krone und für den Ruhm des Königs, wäre die conquista unerlaubt.

Montesquieu vertritt in seinen Römern eine historische Kriegslehre, in den Reflexionen über das zeitgenössische Europa jedoch eine utilitaristische bis humanitäre Kriegstheorie im Rahmen des Völkerrechts und des aktuellen Zivilisationsbewusstseins. Und also gibt es mehrere Paradigmen für den Eroberungskrieg: ein erstes, das sich historisch in der Weltherrschaft Roms niederschlägt; ein zweites, das auf »Erwerb « setzt und den Nutzen kalkuliert; und ein drittes, das kulturkritisch Eroberungskriege mit despotischer Herrschaft kombiniert. Ein Eroberungsstaat aber (Etat Conquérant) habe in Europa, das als eine aus mehreren Nationen gebildete Gesamtnation zu sehen sei (une Nation composée de plusieurs), keine Rechtfertigung mehr.

Kant entwickelt seine Ansichten über den Krieg zunächst im Rahmen von Anthropologie und Geschichtsphilosophie, wo er sie funktional und teleologisch einsetzt: Natur wähle, um zu ihrem Zweck zu gelangen, den Krieg als ihr Mittel. Sie stelle die menschliche Gattung vor Probleme, deren Auflösung dank der immer unerträglicher werdenden Kriegslasten zuletzt ebenso dringlich wie auch real möglich würde: einerseits das Volk vor der Schlaffheit und dem Egoismus des Handelsgeis- 
tes zu bewahren, andererseits die Bereitschaft der Staatsoberhäupter wachsen zu lassen, einen Sicherheit schaffenden Völkerbund zu verabreden. Erst in seiner Moral- und Rechtslehre, und darin in seinem philosophischen Entwurf Zum ewigen Frieden (1795), ersetzt Kant die Lehre von der Unvermeidlichkeit des Krieges durch eine Lehre von der Pflicht zum Frieden. Intervention und Eroberung sind nicht länger zu rechtfertigen, was einem geschichtsphilosophischen Interesse entspricht: dem Schutz revolutionärer Errungenschaften gegenüber der feudalen Reaktion.

\section{Kriegspropaganda}

Es mag sein, daß Benjamin Constant mit seinem Appell an die liberale und humanitäre Zivilisation Europas und den Ausschluss des Eroberers aus der Menschheitsgemeinschaft den Nerv seiner Zeitgenossen traf. Der Pazifismus hat andere Voraussetzungen. ${ }^{67}$ Die Befreiungskriege gegen das napoleonische System waren - im Sinne Constants - keine »eigentlichen Kriege « und enthielten doch die Keime zu nationalen Eroberungskriegen in sich. Seit jeher verlangte das Publikum nach Berichten über geschehene Ereignisse und wurde dabei zum Adressaten politischer und militärischer Propaganda - auch zum Adressaten humanitärer Friedenspropaganda, für die sich der Pazifismus als Partei über den Kriegsparteien anbot (»lieber rot als tot«). Mit dem Briand-Kellog-Prakt wurde der Boden verlassen, auf dem Carl Schmitt den »gehegten Krieg « als ein Duell vor Zeugen bestimmen konnte: Die Staaten erkennen sich nicht länger als »satisfaktionsfähige Ehrenmänner « an, sie führen den Krieg nicht mehr als ein »vor Zeugen sich abspielendes Messen der Kräfte«.68 Vielmehr bemühen sie sich darum, das Publikum - das eigene, das gegnerische wie das neutrale - parteilich zu beeinflussen, nämlich von der eigenen Rolle als eines Verteidigers gegen Aggression und Eroberung und als eines Beschützers vor der Verletzung von Menschenrechten. Propaganda agiert dabei auf einem eigenen, "zweiten« Kriegsschauplatz, der die Ereignisse des ersten interpretiert, um die Moral der Freunde zu heben, die der Feinde zu schwächen und die Sympathie einer neutralen Öffentlichkeit zu gewinnen - oft genug in freiem Umgang mit den Tatsachen.

Die heute üblich gewordene telekommunizierte Information und Bilderschau hat Propaganda vollends zu einem vom »wirklichen Krieg « unabhängigen Kriegsschauplatz gemacht (cyberwar). »In keinem Fall kommt man der Wirklichkeit so schwer auf die Spur wie im Krieg. Dann geht es nicht nur um Eroberung oder die Vernichtung der Feinde, sondern auch um die Herrschaft über die Informationen und deren Deutung. Und die Methoden der Manipulateure verfeinern sich mit der Technik. Dabei bleibt die Wahrheit nicht erst mit Kriegsausbruch auf der Strecke. ${ }^{69}$ Kriegs-

67 Ulrich Matz, Realistische und utopische Friedensmodelle in historischer Perspektive, in: Bernd Rill, Hg., Völkerrecht und Friede, Heidelberg 1995, S. 90-106; Volker Gerhardt, Immanuel Kants Entwurf »Zum Ewigen Frieden«, Darmstadt 1995; Otfried Höffe, Hg., Zum ewigen Frieden, Berlin 1995.

68 Carl Schmitt, Nomos der Erde, Berlin 1950, S. 115, 158.

69 Thomas Hauser, »Kaukasisches Lügengebilde«, in: Badische Zeitung vom 13. 8. 2008, S. 4. 
parteien, die dazu in der Lage sind, streben danach, neutrale Berichterstattung und feindliche Propaganda ganz auszuschalten. Ein Monopol über Nachrichten und Bilder sichert die Deutungshoheit über den Krieg, über Ereignisse die stattgefunden haben und über Ereignisse, die stattgefunden haben könnten.

Die Wahrheit über Ereignisse auf dem Kriegsschauplatz aber war von Machiavelli bis Kant und Constant eine Bedingung der Möglichkeit rational begründbaren militärischen und politischen Handelns und der Beteiligung des Publikums als »Zeugen $\ll$.

\section{Zusammenfassung}

Briand und Kellogg (1928) waren nicht die ersten, das Recht der Staaten zum Krieg (ius belli) aufzukündigen. Auch die Theologen der Schule von Salamanca haben sich schon daran versucht. In unserem Beitrag werden Ansätze zur rechtlichen, politischen und ökonomischen Beschränkung des Eroberungskrieges demonstriert, wobei klassische Texte der frühen Neuzeit bis hin zum beginnenden 19. Jahrhundert die Grundlage bilden: Krieg und Eroberung im Italien der Medici (Machiavelli), im Spanien Karls V. (Vitoria), in Frankreich im Bann des Sonnenkönigs (Montesquieu), in Preußen angesichts der Französischen Revolution (Kant). Im Frühliberalismus wurde in Auseinandersetzung mit Napoleon (Benjamin Constant) der argumentative Höhepunkt der Perhorreszierung des Angriffs- und Eroberungskriegs erreicht. Von hier aus ist es ein kleiner Schritt zur Kriegspropaganda. Seit dem I. Weltkrieg versuchen kriegsführende Staaten mittels Propaganda, Angriffsund Revanchekriege als Verteidigungskriege zu inszenieren.

\section{Abstract}

Till the Briand-Kellogg-treaty (1928) wars of aggression and conquest were based on the ins belli, which legitimated sovereign powers to make war in the interest of their foreign policies. However in the Catholic Conquista in the $16^{\text {th }}$ century

Strong arguments restricting the jus ad bellum were introduced by spanish scholars of theology. - In this essay different approaches to restrict states right of wats are analysed in texts of classic authors on War and Conquest in the time of: the Medici-Dynasty in Italy (Machiavelli), Carlos V of Spain (Vitoria), Louis XIV's political influence on France and in Prussia during the French revolution (Kant). In the early liberal period the moral and civil arguments against war of aggression reached a climax in challenging Napoleon (Benjamin Constant).

Mathias Erzberger, a german politician in the foreign ministry in Berlin with responsibility for propaganda during the I World War, hoped to win sympathy of the public in neutral states by underlying efforts of german self defense instead of military invincibility advocated by the headquarters.

Paul-Ludwig Weinacht, About wars of conquest and propaganda of war 